\title{
Enem: análise do desempenho escolar nas edições de 2009 a 2013
}

\author{
Enem: analysis of school performance in editions 2009-2013
}

\author{
Lindomar Wessler Boneti* \\ Geisa Melo de Oliveira*
}

\section{Resumo}

Trata-se de analisar dados originados de uma pesquisa sobre os resultados do Exame Nacional do Ensino Médio (Enem), nas edições de 2009 a 2013, buscando responder às seguintes questões: a partir dos dados coletados pelas edições do Enem de 2009 a 2013, qual a relação entre a nota obtida e a localização geográfica da escola em relação à situação social e econômica regional? Como interpretar teoricamente os parâmetros de avaliação utilizados pelo Enem? Os procedimentos metodológicos adotados foram: análise documental e análise de dados coletados dos sites oficiais do Ministério da Educação (MEC) e do Instituto Nacional de Estudos e Pesquisas Educacionais Anísio Teixeira (Inep), assim como o estudo teórico e bibliográfico. O estudo aponta que na Região Nordeste aparece um maior número de escolas ocupando posições de fragilidades no ranking das instituições, em todas as edições pesquisadas, e que não há nenhuma instituição privada ou pública federal na listagem com as piores notas. Finalmente, dialogando com Pièrre Bourdieu e Jean-Claude Passeron (1985, 1992), o estudo aponta para uma explicação teórica do fenômeno a partir da legitimação do contexto das desigualdades sociais até a legitimação das desigualdades regionais.

Palavras-chave: Enem. Políticas educacionais. Ranking educacional.

\section{Abstract}

This article is part of a Master's research and analyzes the results of the National High School Exam (Enem), issues 2009-2013, seeking to answer a central question: What the data collected editions 2009, 2010, 2011, 2012 and 2013, said to us about the schools that got the worst grades in these editions of the exam? The adopted methodological procedures were: documents and data analysis (colected documents from the internet sites such as MEC and Inep) and bibliographical. The study leads to the conclusion that Northeast region is the only one that always have schools occupying positions in the ranking of educational institutions with the worst Enem's grades in all editions surveyed; that despite the efforts made by the MEC and Inep to make it fair disclosure of data, this goal has not been achieved; and that there is no private schools or federal public institutions in the list with the worst grades. Finally, the article points to some questions about the reasons that lead these schools to submit or not such results and some suggestions on what could be done to prevent this.

Keywords: Enem. Educactional Policies. Educational Ranking.

Recebido em: 09/12/2016 - Aprovado em: 13/06/2017

http://dx.doi.org/10.5335/rep.v24i2.7420

Professor do Programa de Pós-Graduação em Educação da Pontifícia Universidade Católica do Paraná - PUCPR. Doutor em Sociologia pela Université Laval Québec, Canadá, com pós-doutorado no Departamento de Ciências da Educação da Université de Fribourg, Suiça. E-mail: lindomar@boneti.com

** Graduada em Sociologia e mestre em Educação pela Pontifícia Universidade Católica do Paraná (PUCPR). E-mail: geisaoliveira@yahoo.com.br 


\section{Introdução}

Este artigo tem origem em uma inquietação que pode ser resumida em duas questões básicas: a partir dos dados coletados pelas edições do Exame Nacional do Ensino Médio (Enem) de 2009 a 2013, qual a relação entre a nota obtida e a localização geográfica da escola em relação à situação social e econômica regional? Como interpretar teoricamente os parâmetros de avaliação utilizados pelo Enem?

Os procedimentos metodológicos adotados foram a análise documental e a análise de dados coletados dos sites oficiais do Ministério da Educação (MEC) e do Instituto Nacional de Estudos e Pesquisas Educacionais Anísio Teixeira (Inep), assim como o estudo teórico e bibliográfico.

O Enem é uma política pública educacional do governo federal implementada em 1998, que surgiu com a finalidade de "avaliar o desempenho do estudante ao fim da educação básica, buscando contribuir para a melhoria da qualidade desse nível de escolaridade", entretanto, "a partir de 2009, o Enem passou a ser utilizado também como mecanismo de seleção para o ingresso no ensino superior". ${ }^{1}$

O conceito de políticas públicas adotado neste artigo segue a definição de Kauchakje (2008). Segundo o autor, políticas públicas são: “[...] formas de planejamento governamental visando coordenar os meios e recursos à disposição do Estado, e também do setor privado e suas atividades, para a realização de objetivos e ações 'socialmente relevantes e politicamente determinados"' (2008, p. 71).

Boneti (2011), entretanto, amplia a abrangência do significado, o que será de suma importância na abordagem dos próximos capítulos deste trabalho, haja vista que serão consideradas políticas públicas educacionais não somente os investimentos do governo (observados do ponto de vista meramente orçamentário), mas também suas medidas administrativas que, de alguma forma, interfiram direta ou indiretamente na educação:

[...] política pública não se resume na ação do Estado em termos de investimento social, mas, antes de tudo, em conjuntos de ações que buscam construir um real futuro. Dessa forma, seria de se considerar, também, que medidas de intervenção meramente administrativas, por parte do Estado, sem mesmo envolver orçamento público, são consideradas políticas públicas. Isto é, existe a possibilidade, no estudo das políticas públicas, de se fazer uma análise interligando a ação pública de mera intervenção administrativa e o do investimento pelo Estado (2011, p. 9).

Importante ressaltar, também, o conceito de avaliação utilizado neste artigo. Para Dalben, no início: 
A avaliação escolar como um campo teórico de conhecimento centrou-se, por muito tempo, nos estudos sobre o rendimento escolar dos alunos, e nos resultados dos processos de aprendizagem. Originou-se daí a concepção predominante de avaliação escolar como um processo de medida do desempenho em face de objetivos educacionais prévios, numa perspectiva técnica, com ênfase na representação quantificada do conhecimento adquirido por meio de notas ou conceitos (2002, p. 14).

Entretanto, ainda de acordo com Dalben, a partir da década de 1970, com a crise do petróleo, tem início um período de mudança do papel do Estado, que, de provedor, passa também a fiscalizador das políticas públicas em geral:

Nos Estados Unidos, por exemplo, o governo sinaliza como sua principal meta a promoção e o aumento da competitividade dos norte-americanos no mercado internacional, intensificando para isso a prática de aplicação de testes padronizados de alcance nacional para verificação dos níveis de educabilidade do povo, elaborando um sistema de indicadores internacionais para definir padrões de qualidade e adotando currículos mínimos de âmbito nacional como forma de controle da oferta e do produto (DALBEN, 2002, p. 26).

Tal modelo foi exportado para o mundo, o que levou a uma proliferação de testes e avaliações extraescolares, tanto em nível nacional quanto em nível internacional (como o Pisa, por exemplo).

O Enem foi implementado pela primeira vez no ano de sua criação (1998), contendo 63 questões e uma redação. Em 2005, acrescentou-se o objetivo de avaliação dos estudantes ao final da educação básica, a concessão de bolsas em instituições privadas de ensino superior e, em 2009, passou por uma reformulação tanto na sua utilização (acesso ao ensino universitário público) quanto na sua aplicação, que passou a contar com dois dias de prova, totalizando 180 questões distribuídas em quatro cadernos: Ciências Humanas e suas Tecnologias, Ciências da Natureza e suas Tecnologias, Linguagens e Códigos e suas Tecnologias e Matemáticas e suas Tecnologias, além da redação.

$\mathrm{O}$ recorte da pesquisa que baseou este artigo não considerou unidades da federação específicas, mas o resultado geral do Enem, nas edições de 2009 a 2013. A razão para essa escolha é parte do objetivo de, em se tratando de uma análise de uma política pública avaliativa federal e, portanto, válida para todo o território nacional, tentar compreender as consequências da divulgação dos seus resultados da forma como são apresentados na atualidade. Além disso, objetiva-se formular perguntas que suscitem novas pesquisas, para melhorar tanto a forma de divulgação como a forma de compreensão dessa divulgação. O período de análise (2009-2013) também foi estabelecido por serem todas essas edições posteriores às mais significativas transformações implementadas pelo MEC, tanto no formato de aplicação das provas quanto nas finalidades e possíveis utilizações. 
Cabe ressaltar, também, no que se refere à divulgação das notas do exame, que, em todas as edições, o MEC e o Inep estabelecem critérios de divulgação das notas e incluem no ranking de divulgação apenas as instituições de ensino, sejam públicas ou privadas, que tenham a participação mínima de 10 alunos nas provas e cujo percentual de participação nas provas seja superior a $50 \%$.

Por se tratar de um país de dimensões continentais, com cultura e condições socioeconômicas muito diversas dentro de seu território, a análise desses resultados deveria ser feita:

Considerando-se que as instituições são diferentes entre si, [...] a importância de se analisarem as condições sociais da população a que se destina a escola, o contexto econômico-cultural em que está inserida e as políticas educacionais que a orientam (VIEIRA, 2013, p. 67).

Entretanto, o que se vê, frequentemente, na mídia e na vida cotidiana, é um uso equivocado dos resultados - tanto como forma de propaganda gratuita das unidades de ensino que alcançam as melhores notas e, portanto, colocações no topo do ranking quanto como forma de desvalorização das escolas que, por vários fatores conjuntos, não alcançam o resultado esperado. Com relação à metodologia utilizada, de acordo com o proposto por Vieira (2013, p. 70), serão analisados textos legais e documentos emanados do poder central, estatísticas oficiais e publicações exteriores à escola, livros, artigos de jornais e revistas, etc.

O artigo está divido em cinco partes que correspondem aos anos de aplicação do Enem, de 2009 a 2013, e apresentam os resultados das dez instituições de ensino brasileiras que obtiveram os dez piores resultados no exame, respectivamente, além de uma última parte, tratando das considerações finais desta pesquisa, que pretendeu apontar questionamentos a respeito da forma e dos usos dos resultados do Enem.

\section{Resultado da edição Enem 2009}

Em 19 de julho de 2010, foram divulgados os resultados do Enem realizado em 2009. De acordo com os dados coletados no site oficial de divulgação - MEC/Inep -, as dez instituições de ensino que obtiveram os piores resultados nessa edição estão na Tabela 1. 
Tabela 1 - Escolas com as dez piores notas do Enem 2009

\begin{tabular}{l|l|l|l|l|l}
\hline Posição & UF & \multicolumn{1}{|c|}{ Município } & \multicolumn{1}{|c|}{ Nome da instituição } & Média total & \multicolumn{1}{c}{ Rede } \\
\hline $1^{\text {a }}$ & AM & Santo Antônio do lçá & E. E. Indígena Dom Pedro I & 249,25 & Estadual \\
$2^{\circ}$ & MT & Paranatinga & E. E. Osvaldo C. Pereira & 307,42 & Estadual \\
$3^{\circ}$ & MA & São Luís & C. E. Vicente Maia & 320,02 & Estadual \\
$4^{\circ}$ & MA & Buriticupu & C. E. Profa. Juvenilia Soares Sousa & 345,82 & Estadual \\
$5^{\circ}$ & BA & Salvador & C. E. Georgina Ramos da Silva & 346,67 & Estadual \\
$6^{\circ}$ & MG & Argirita & E. E. Prof. Luiz Antonio Pires Souza & 349,4 & Estadual \\
$7^{\circ}$ & RO & Nova Brasilândia do Oeste & C. E. E. J. A. Cecília Meireles & 352,83 & Estadual \\
$8^{\circ}$ & RJ & Macaé & C. M. Aroeira & 353,09 & Municipal \\
$9^{\circ}$ & MA & Bacuri & C. E. Cristino Pimeira - Anexo II & 354,93 & Estadual \\
$10^{\circ}$ & PA & Tucuruí & E. E. E. M. Ana Ponte Francez & 357,03 & Estadual \\
\hline
\end{tabular}

Fonte: elaboração dos autores com base em dados dos sites do MEC (disponível em: <http://portal.mec.gov.br/>), do Inep (disponível em: <http://www.inep.gov.br/>) e da Folha de S. Paulo (disponível em: <http://www1.folha.uol. com.br/educacao/2014/12/1566017-confira-o-desempenho-de-cada-escola-do-pais-no-enem-2013.shtml>). Acessos em: 20 mar. 2015.

Cabe observar que, em Nota Técnica, o Inep esclarece alguns critérios que foram utilizados no Enem 2009 para a divulgação de seus resultados:

Os critérios de divulgação das Médias do ENEM 2009 por escola são:

I. Se a escola obteve taxa de participação inferior a $2 \%$, nenhuma de suas médias será divulgada;

II. Se a escola possuir pelo menos 10 (dez) alunos que participaram do ENEM 2009 e realizaram as provas objetivas das 4 (quatro) Áreas de Conhecimento e a taxa de participação da escola não for inferior a $2 \%$, essa terá suas Médias por Área de Conhecimento e Média nas Objetivas divulgadas;

III. Se a escola possuir pelo menos 10 (dez) alunos que participaram do ENEM 2009, fizeram a Redação, e a taxa de participação não for inferior a $2 \%$, essa terá sua média de Redação divulgada;

IV. Se a escola possuir pelo menos 10 (dez) alunos que participaram do ENEM 2009 e realizaram as provas objetivas das 4 (quatro) Áreas de Conhecimento, pelo menos 10 alunos que participaram do ENEM 2009 e fizeram a Redação e, ainda, a taxa de participação não for inferior a $2 \%$, essa terá sua média total divulgada.

As escolas que não atenderam um ou mais critérios citados tiveram suas notas substituídas pela sigla SC (Sem Cálculo).

As escolas que não possuem o Nível de ensino e/ou a Modalidade considerada para o cálculo das médias não serão divulgadas.

Além das médias mencionadas, outras três informações importantes para a análise dos resultados são apresentadas: 1) o número de alunos matriculados no Ensino Médio Regular e/ou Educação de Jovens e Adultos de cada escola, 2) o número de concluintes do Ensino Médio que participaram do ENEM 2009 e realizaram as provas objetivas das 4 (quatro) Áreas de Conhecimento, e 3) o número de concluintes do Ensino Médio que participaram do ENEM 2009 e fizeram a Redação. ${ }^{2}$ 
Nessa edição, 25.484 escolas de ensino médio e 2.426.432 candidatos participaram do exame. Assim, pelo critério de divulgação, percebe-se uma distorção muito grande entre o número de alunos dos colégios e o percentual de participantes. Por exemplo, a Escola Estadual Indígena Dom Pedro I tinha 58 alunos, dos quais 40 participaram do Enem 2009 - o que corresponde a 68,9\% de participação. Já a E. E. E. M. Ana Ponte Francez tinha 257 alunos, e apenas 16 participaram do Enem 2009 - o que corresponde a 6,23\% de participação. Tal informação por si só já impede que se faça uma comparação válida entre essas escolas, à medida que um número de participantes menor pode ser fruto de uma seleção dos melhores alunos - seja por incentivos da escola seja porque, por ser se tratar de um exame não obrigatório para os concluintes do ensino médio, apenas os alunos mais interessados em ingressar em uma universidade e, consequentemente, mais estudiosos tenham participado da prova.

De qualquer forma, por mais questionável que seja a comparação, cabe ressaltar que, das dez escolas com os piores resultados do Enem 2009, todas são instituições públicas de ensino, sendo três pertencentes à Região Norte (estaduais), quatro pertencentes à Região Nordeste (todas estaduais), duas pertencem à Região Sudeste (uma estadual e uma municipal) e uma pertence à Região Centro-Oeste (estadual).

Mesmo que as escolas que obtiveram os melhores resultados não sejam o foco deste artigo, é interessante notar que a diferença de notas entre a escola que obteve o melhor resultado e a escola que obteve o pior resultado é de 500,45 pontos. Dentre as escolas que obtiveram os melhores resultados no Enem 2009, há duas instituições de ensino da Região Nordeste (privadas), seis da Região Sudeste (uma federal e cinco privadas) e duas da Região Centro-Oeste (privadas).

Retornando à lista com as escolas que obtiveram as piores notas, verifica-se, também, que, dentre as dez escolas, apenas duas se localizam nas capitais de seus respectivos estados.

\section{Resultado da edição Enem 2010}

Em 12 de setembro de 2011, foram divulgados os resultados do Enem realizado em 2010. De acordo com os dados coletados no site oficial de divulgação MEC/Inep -, as dez instituições de ensino que obtiveram os piores resultados nessa edição estão na Tabela 2. 
Tabela 2 - Escolas com as dez piores notas do Enem 2010

\begin{tabular}{l|l|l|l|l|l}
\hline Posição & \multicolumn{1}{|c|}{ UF } & \multicolumn{1}{|c|}{ Município } & \multicolumn{1}{|c|}{ Nome da instituição } & Média total & \multicolumn{1}{c}{ Rede } \\
\hline $1^{\underline{a}}$ & SP & Bertioga & Txeru Ba e Kua - I & 432 & Estadual \\
$2^{\underline{a}}$ & ES & Afonso Claudio & E. E. E. F. M. José Roberto Christo & 435,13 & Estadual \\
$3^{\underline{a}}$ & PI & Santa Rosa do Piauí & E. M. Francisco José dos Santos & 439,63 & Municipal \\
$4^{\underline{a}}$ & ES & Divino de São Lourenço & E. E. E. F. M. Juvenal Nolasco & 446,97 & Estadual \\
$5^{\underline{a}}$ & ES & Cachoeiro de Itapemirim & E. E. E. M. Pacotuba & 447,25 & Estadual \\
$6^{\underline{a}}$ & PI & Madeiro & U. E. Santa Teresinha & 448,31 & Estadual \\
$7^{\underline{a}}$ & ES & Água Doce do Norte & E. E. E. F. M. Olegário Martins & 450,4 & Estadual \\
$8^{\underline{a}}$ & MA & Tuntum & C. E. José Pinheiro & 450,91 & Estadual \\
$9^{\underline{a}}$ & ES & Irupi & E. E. E. M. Santa Cruz & 452,36 & Estadual \\
$10^{\underline{a}}$ & CE & Itapipoca & Anastácio Alves Braga E. E. F. M. & 453,66 & Estadual \\
\hline
\end{tabular}

Fonte: elaboração dos autores com base em dados dos sites do MEC (disponível em: <http://portal.mec.gov.br/>), do Inep (disponível em: <http://www.inep.gov.br/>) e da Folha de S. Paulo (disponível em: <http://www1.folha.uol. com.br/educacao/2014/12/1566017-confira-o-desempenho-de-cada-escola-do-pais-no-enem-2013.shtml>). Acessos em: 20 mar. 2015.

Em 2010, 26.099 escolas e 3.242.776 candidatos fizeram o exame. Com relação à divulgação dos resultados, em primeiro lugar, cabe destacar que, no ano de 2011, o MEC e o Inep alteraram o critério de divulgação dos resultados do Enem 2010. Naquele ano, a divulgação das notas do Enem dividiu as escolas participantes em quatro grupos, de acordo com o percentual de alunos participantes no exame: Grupo 1: as 4.640 escolas que tiveram mais de $75 \%$ de seus estudantes participando do Enem 2010; Grupo 2: as 5.444 escolas que tiveram de 50\% a $75 \%$ de alunos participando do exame; Grupo 3: as 8.616 escolas com participação de $25 \%$ a $50 \%$ de seus alunos; e Grupo 4: as 7.399 escolas com participação de $2 \%$ a $25 \%$ de seus alunos. Tal alteração na divulgação das notas teve por objetivo diminuir a discrepância no ranking escolar percebido em 2009, quando escolas com índices de participação muito diversos foram colocadas na mesma listagem.

Sendo assim, os resultados da Tabela 2 referem-se às escolas cujo índice de participação no Enem 2010 foi superior a 75\%. Esse critério de divulgação eliminou a distorção número de alunos/número de participantes, fazendo com que todas as escolas dessa lista tivessem um índice de participação muito próximo. Somente a título de exemplificação, traz-se à colação a escola Txeru Ba e Kua-I, com 17 alunos e 14 participantes; a Anastácio Alves Braga E. E. F. M., com 103 alunos e 103 participantes; e o C. E. José Pinheiro, com a maior diferença: 77 alunos e 58 participantes. 
Destaca-se que, das dez escolas, quatro são da Região Nordeste e seis da Sudeste. As regiões Norte e Centro-Oeste deixaram de figurar na listagem das dez piores notas nesse ano, o que pode ter sido causado pela própria redistribuição do ranking de escolas. Caberia, neste ponto, ao menos duas possíveis indagações: se isso se deve ao fato de essas regiões contarem com menor número de estudantes participantes em cada unidade escolar (o que faria com que essas unidades não figurassem no ranking de $75 \%$ a $100 \%$ de participação na prova) ou se a aprendizagem dos alunos dessa região melhorou a ponto de suas unidades escolares não mais aparecerem no ranking das dez piores notas.

Outro ponto que merece atenção é o fato de a pior nota ter sido obtida por uma escola indígena localizada em Bertioga, SP, e que não tem a língua portuguesa como sua língua oficial.

Ressalta-se, também, que nenhuma das escolas presentes nessa lista está localizada na capital de seu estado e que a diferença de pontos entre a primeira colocada no ranking e a última diminui para 329,70 pontos, o que, mais uma vez, nos faz indagar se isso não poderia ser efeito da mudança de divulgação do ranking, já que, nesse ranking, encontram-se apenas as escolas com índice de participação de $75 \%$ a $100 \%$.

Embora não seja esse o foco do artigo, cabe observar, a título de informação complementar, que, das dez escolas que obtiveram as melhores notas no Enem 2010, nove são instituições privadas de ensino e uma é pública federal.

\section{Resultado da edição Enem 2011}

Em 22 de novembro de 2012, foram divulgados os resultados do Enem 2011. De acordo com os dados coletados no site oficial de divulgação - MEC/Inep -, as dez instituições de ensino que obtiveram os piores resultados nessa edição estão na Tabela 3. 
Tabela 3 - Escolas com as dez piores notas do Enem 2011

\begin{tabular}{l|l|l|l|l|l}
\hline Posição & UF & \multicolumn{1}{|c|}{ Município } & \multicolumn{1}{|c|}{ Nome da instituição } & $\begin{array}{c}\text { Média } \\
\text { total }\end{array}$ & \multicolumn{1}{c}{ Rede } \\
\hline $1^{\text {á }}$ & MA & São Domingos do Azeitão & C. E. Aquiles Lisboa & 383,71 & Estadual \\
$2^{\circ}$ & PI & Francisco Ayres & U. E. João Pereira de Sousa & 391,39 & Estadual \\
$3^{\circ}$ & MA & Olinda Nova do Maranhão & C. E. José Maria de Araújo - Anexo I & 393,52 & Estadual \\
$4^{\circ}$ & SP & Taquarituba & Dimas Mozart e Silva Prof. & 394,48 & Estadual \\
$5^{\circ}$ & MA & Centro Novo do Maranhão & C. E. Maria do Socorro Almeida Ribeiro & 394,55 & Estadual \\
$6^{\circ}$ & MA & Buriti Bravo & C. E. Profa. Leda Tajra - Anexo Juçara & 396,54 & Estadual \\
$7^{\circ}$ & PB & Aguiar & E. M. E. I. E. F. C. N. N. M. Lídia Cabral de Sousa & 396,69 & Estadual \\
$8^{\circ}$ & ES & Serra & E. E. E. F. M. Getúlio Pimentel Loureiro & 396,81 & Municipal \\
$9^{\circ}$ & MG & Além Paraíba & E. E. Dr. Alfredo Castelo Branco & 396,97 & Estadual \\
$10^{\circ}$ & MA & Benedito Leite & C. E. Lucas Coelho & 397,20 & Estadual \\
\hline
\end{tabular}

Fonte: elaboração dos autores com base em dados dos sites do MEC (disponível em: <http://portal.mec.gov.br/>), do Inep (disponível em: <http://www.inep.gov.br/>) e da Folha de S. Paulo (disponível em: <http://www1.folha.uol. com.br/educacao/2014/12/1566017-confira-o-desempenho-de-cada-escola-do-pais-no-enem-2013.shtml>). Acessos em: 20 mar. 2015.

Em 2011, o MEC e o Inep alteraram novamente a forma de divulgação dos resultados, para tentar eliminar as distorções e tornar mais justa a comparação entre as diferentes instituições de ensino:

Este ano, o INEP decidiu divulgar as médias por Área do Conhecimento e para Redação, apenas para as escolas que obtiveram no mínimo 50\% de seus estudantes concluintes do Ensino Médio Regular participando de todas as provas do ENEM 2011. Mesmo para as escolas com Taxa de Participação igual ou maior que 50\%, os estudantes participantes podem não representar o desempenho médio que a escola obteria caso todos os estudantes participassem do exame, portanto, é importante observar a Taxa de Participação de cada escola. Outra mudança adotada é a divulgação das médias apenas para cada Área do Conhecimento e para Redação, não havendo mais a divulgação de uma única média por escola. Portanto, as escolas poderão continuar comparando suas médias por Área do Conhecimento para avaliarem o desempenho de seus estudantes. ${ }^{3}$

Nesse caso, a média final da Tabela 3 refere-se às notas das provas objetivas, desconsiderando as notas da redação. Das escolas que obtiveram as piores notas nessa edição do exame, sete pertencem à Região Nordeste e três à Região Sudeste. Uma inversão dos resultados da edição 2010, que registrou quatro instituições da Região Nordeste e seis da Sudeste. Pelo segundo ano consecutivo, as instituições de ensino da Região Norte e da Região Centro-Oeste não estão presentes na lista das dez instituições de ensino com as piores notas. Mais uma vez, caberia indagar aos números se, e em que medida, as alterações ocorridas na divulgação dos resultados 
do Enem interferiram nessas ausências. Observa-se, também, que as médias das escolas com as piores colocações no ranking 2011 foram mais baixas do que no ano anterior. Para se ter uma ideia, o último colocado da edição 2010 obteve 432 pontos, e o último colocado dessa edição obteve 383,71 pontos. A diferença de pontuação da escola que teve a melhor nota para a escola que obteve a pior nota foi de 353,44 pontos.

Novamente, nenhuma das instituições de ensino que obtiveram as piores notas é localizada na capital do seu estado. Dentre as instituições escolares que obtiveram as melhores notas no Enem 2011, foi recorrente, nove são instituições privadas de ensino e apenas uma é pública federal.

\section{Resultado da edição Enem 2012}

Em 28 de dezembro de 2012, foram divulgados os resultados do Enem realizado em 2012. De acordo com os dados coletados no site oficial de divulgação MEC/Inep -, as dez instituições de ensino que obtiveram os piores resultados nessa edição estão na Tabela 4.

Tabela 4 - Escolas com as dez piores notas do Enem 2012

\begin{tabular}{|c|c|c|c|c|c|}
\hline Posição & UF & Município & Nome da instituição & $\begin{array}{l}\text { Média } \\
\text { objetiva }\end{array}$ & Rede \\
\hline $1^{\mathrm{a}}$ & AM & São Gabriel da Cachoeira & E. E. Dom Pedro Massa & 399,1 & Estadual \\
\hline $2^{\mathrm{a}}$ & PA & Cachoeira do Arari & E. E. E. F. M. Retiro Grande & 399,3 & Estadual \\
\hline $3^{\mathbf{a}^{a}}$ & $A C$ & Porto Acre & E. C. José Plácido de Castro & 399,5 & Estadual \\
\hline $4^{\underline{a}}$ & AM & Parintins & E. E. de Caburi & 401,0 & Estadual \\
\hline $5^{\mathrm{a}}$ & MS & Aquidauana & $\begin{array}{l}\text { E. E. Indígena de E. M. Pastor Reginaldo } \\
\text { Miguel - Hoyeno O }\end{array}$ & 402,9 & Estadual \\
\hline $6^{\mathrm{a}}$ & TO & São Felix do Tocantins & E. E. Sagrado Coração de Jesus & 403,9 & Estadual \\
\hline $7^{\underline{a}}$ & PA & Colares & E. E. E. F. Dr. José Malcher & 404,0 & Estadual \\
\hline $8^{\underline{a}}$ & $A C$ & Xapuri & E. São Miguel & 406,2 & Estadual \\
\hline $9^{\underline{a}}$ & MA & São Domingos do Azeitão & C. E. Aquiles Lisboa & 406,4 & Estadual \\
\hline $10^{\mathrm{a}}$ & PR & Grandes Rios & Floriano Peixoto C. E. Mal. E. F. M. & 407,4 & Estadual \\
\hline
\end{tabular}

Fonte: elaboração dos autores com base em dados dos sites do MEC (disponível em: <http://portal.mec.gov.br/>), do Inep (disponível em: <http://www.inep.gov.br/>) e da Folha de S. Paulo (disponível em: <http://www1.folha.uol. com.br/educacao/2014/12/1566017-confira-o-desempenho-de-cada-escola-do-pais-no-enem-2013.shtml>). Acessos em: 20 mar. 2015. 
Observa-se que todas as dez instituições de ensino brasileiras que obtiveram os piores resultados no Enem 2012 são instituições públicas estaduais. Nota-se, também, que, dentre essas dez instituições de ensino, há uma única localizada na Região Sul, uma localizada na Região Centro-Oeste, sete localizadas na Região Norte e uma localizada na Região Nordeste. Constata-se que, novamente, nenhuma das instituições de ensino que obtiveram as piores notas do Enem 2012 se localiza na capital de seu estado.

Comparando-se os resultados da primeira e da última colocadas no Enem 2012, constata-se que há uma diferença de 323,1 pontos, o que, num primeiro momento de análise, aponta para um grande déficit de aprendizagem dos alunos da última colocada quando comparados aos da primeira colocada, considerando apenas a pontuação de cada uma delas. Entretanto, houve uma ligeira elevação da nota das escolas que obtiveram as piores notas no Enem 2012.

De acordo com a Agência Brasil: ${ }^{4}$

Os alunos das escolas públicas federais conseguiram a maior média no Exame Nacional do Ensino Médio (Enem) de 2012, de acordo com o Ministério da Educação (MEC). A rede obteve média de 584,23 pontos em uma escala que vai até 1.000 . As escolas privadas aparecem em seguida com 577,39 pontos.

[...]

A rede federal atende a $2 \%$ dos estudantes do ensino médio que fizeram o Enem no ano passado. A rede privada concentra $31,51 \%$ dos estudantes. A maior parte dos estudantes concluintes do ensino médio participantes do exame está na rede pública estadual de ensino, $65,53 \%$. A rede obteve uma média geral de 485,64 pontos e uma média na redação de 491,41. A rede pública municipal, com $0,95 \%$ dos estudantes, obteve uma média de 524,14 em toda a prova e 533,48 pontos na redação. ${ }^{5}$

Cabe ressaltar, também, que, na edição de 2012, o Enem contou com a participação de 24.842 escolas e 2.355.335 estudantes.

A partir de 2012, o MEC e o Inep passaram a liberar os resultados individuais de cada aluno também para as escolas, facilitando, assim, um acompanhamento pedagógico mais aprofundado.

A título de comparação com os itens anteriores, na edição de 2012, das dez escolas que obtiveram as melhores notas, houve, pela primeira vez, um aumento no número de instituições públicas que figuram na lista: oito instituições privadas de ensino e duas públicas federais.

\section{Resultado da edição Enem 2013}

Em 22 de dezembro de 2014, o MEC liberou os resultados, por escola, do Enem 2013. A ordem de classificação das dez últimas colocadas no exame é apresentada na Tabela 5. 
Tabela 5 - Escolas com as dez piores notas do Enem 2013

\begin{tabular}{l|l|l|l|l|l}
\hline Posição & \multicolumn{1}{|c|}{ UF } & \multicolumn{1}{|c|}{ Município } & \multicolumn{1}{|c|}{ Nome da instituição } & $\begin{array}{c}\text { Média } \\
\text { objetiva }\end{array}$ & \multicolumn{1}{c}{ Rede } \\
\hline $1^{\circ}$ & MA & Jatobá & C. E. Aluizio Azevedo - Anexo Cachimbos & 397,0 & Estadual \\
$2^{\circ}$ & MT & Jangada & E. E. Benedita Augusta Lemes & 399,3 & Estadual \\
$3^{\circ}$ & MA & Buriti Bravo & C. E. Professora Leda Tajra - Anexo Juçara & 399,3 & Estadual \\
$4^{\circ}$ & AC & Rodrigues Alves & E. Manoel Carneiro de Messias & 402,9 & Estadual \\
$5^{\circ}$ & RN & Ipanguaçu & E. E. Maria da Glória de A Luna E. F. M. & 406,6 & Estadual \\
$6^{\circ}$ & MA & Mirador & C. E. Edison Lobão - Anexo lbipira & 407,4 & Estadual \\
$7^{\circ}$ & PA & Marabá & E. E. E. M. São José & 409,8 & Estadual \\
$8^{\circ}$ & AM & Presidente Figueiredo & E. E. de Balbina & 410,6 & Estadual \\
$9^{\circ}$ & MT & Acorizal & E. E. Ponce de Arruda & 410,8 & Estadual \\
$10^{\circ}$ & TO & Bom Jesus do Tocantins & E. E. Alfredo Nasser & 410,8 & Estadual \\
\hline
\end{tabular}

Fonte: elaboração dos autores com base em dados dos sites do MEC (disponível em: <http://portal.mec.gov.br/>), do Inep (disponível em: <http://www.inep.gov.br/>) e da Folha de S. Paulo (disponível em: <http://www1.folha.uol. com.br/educacao/2014/12/1566017-confira-o-desempenho-de-cada-escola-do-pais-no-enem-2013.shtml>). Acessos em: 20 mar. 2015.

Nota-se que, novamente, todas as dez escolas que ocupam as últimas posições no ranking do Enem 2013 são instituições públicas estaduais. Dessa vez, quatro pertencem à Região Norte do país, quatro à Região Nordeste e duas à Região Centro-Oeste. Uma vez mais, nenhuma das escolas que obtiveram as piores notas se localiza na capital de seu estado. A diferença de pontuação entre a primeira e a última instituição do ranking é de 344,9 pontos.

Dentre essas escolas, os níveis de pontuação permanecem quase inalterados com relação à edição de 2011 do Enem. Mais uma vez, a liberação dos resultados seguiu o critério de divulgação apenas das escolas com participação superior a 50\% e 10 alunos. Mais de 5 milhões de pessoas realizaram o exame em 2013. Nessa edição, o MEC e o Inep acrescentaram dois novos indicadores na divulgação dos resultados do exame: o nível socioeconômico (Inse) ${ }^{6}$ de cada escola e a formação docente. ${ }^{7}$ Essa foi mais uma tentativa desses órgãos de tornar mais justa a comparação entre escolas e estudantes, levando-se em conta os diferentes contextos econômicos e sociais existentes no país.

No que concerne às instituições de ensino que obtiveram as melhores notas na edição 2013 do Enem, houve somente instituições privadas de ensino. 


\section{Considerações finais e novos questionamentos}

Em primeiro lugar, a análise dos resultados das escolas que obtiveram as piores notas no Enem nas edições de 2009 a 2013 demonstra que, em um país tão grande e tão diverso em termos culturais, econômicos e sociais como o Brasil, é muito difícil que uma avaliação de caráter nacional proporcione uma comparação justa entre as diversas unidades escolares participantes.

Em segundo lugar, percebe-se que, ano a ano, o MEC e o Inep vêm tentando aprimorar a forma de divulgação dos resultados, a fim de diminuir a discrepância e a injustiça da comparação de realidades tão diversas.

Constata-se que a Região Nordeste aparece em todas as tabelas demonstrativas dos dez piores resultados do Enem em todas as edições pesquisadas. Outra informação que se pode verificar é que, com exceção do Colégio Estadual Georgina Ramos da Silva, de Salvador, BA, e do Colégio Estadual Vicente Maia, de São Luís, MA, na edição 2009, todas as escolas que figuram nas piores colocações nas referidas edições estão localizadas fora das capitais de seus estados.

Não houve registro de nenhuma instituição privada de ensino entre as últimas posições do Enem. Também não houve nenhuma instituição federal no ranking das dez piores em nenhuma das edições analisadas. Percebe-se, também, que, com exceção do Colégio Municipal Aroeira de Macaé, RJ (edição 2009), da Escola Municipal Francisco José dos Santos de Santa Rosa do Piauí, PI (edição 2010), e da E. M. E. I. E. F. C. N. N. M. Lídia Cabral de Sousa de Aguiar, PB, todas as demais instituições de ensino que ficaram nas dez últimas posições do ranking do Enem nas edições pesquisadas são estaduais.

O conjunto de dados analisados neste artigo suscitaram as seguintes questões sobre as instituições de ensino que obtiveram as piores notas nas cinco edições do Enem analisadas:

1. Por que não há nenhuma instituição de ensino privada ou pública federal na listagem das instituições com as piores notas?

2. O fato de as instituições de ensino que obtiveram os piores resultados no Enem (dos anos analisados) estarem localizadas, em sua grande maioria, fora das capitais dos seus estados é mera coincidência ou, de alguma forma, estar localizada fora da capital faz a unidade de ensino receber menos recursos e apoio, ter menos fiscalização, etc.?

3. Colocar em um mesmo ranking escolas privadas e públicas (que dependem e dispõem de fontes de recursos financeiros diferentes), urbanas e rurais, indígenas ou não é possível, mas é justo? 
4. O fato de escolas públicas - e apenas elas - figurarem no ranking das escolas com o pior aproveitamento, não causa um esvaziamento das escolas públicas e, como consequência, não provoca uma migração de alunos para instituições de ensino privadas?

5. Em caso de resposta afirmativa à questão anterior, não estaria o Enem sendo utilizado como "ferramenta de mercado" ou "propaganda gratuita" pelas instituições de ensino privadas?

6. Por que a Região Nordeste é a única a ter instituições de ensino ocupando posições no ranking das instituições com as piores notas do Enem em todas as edições pesquisadas?

Como este estudo não se restringiu apenas às escolas com as piores classificações, embora esse tenha sido o enfoque do artigo, com relação às escolas que conquistaram as melhores notas nas cinco edições analisadas, surgiram as seguintes perguntas:

1. Apesar de o Enem ser aplicado desde 1998, com o objetivo de avaliar o desempenho do estudante ao fim da educação básica, buscando contribuir para a melhoria da qualidade desse nível de escolaridade, por que, no ranking das escolas com melhor aproveitamento no Enem das cinco edições analisadas, há um número tão pequeno de instituições públicas (apenas uma de 2009 a 2011, duas em 2012 e nenhuma em 2013)?

2. Por que, em todas as edições em que houve instituições públicas figurando na lista das dez melhores notas do Enem, nas cinco edições analisadas, todas eram federais?

3. Será que, de certa forma, como geralmente as instituições públicas federais de ensino realizam um processo seletivo prévio para o preenchimento de suas vagas - pela grande procura de alunos por vagas -, essas instituições já não têm alunos diferenciados (mais estudiosos, com maior capital cultural, maior capital econômico, etc.), e isso não facilitaria a conquista de melhores resultados?

4. Nesse caso, é justo colocar instituições federais de ensino no mesmo ranking das instituições estaduais, que não fazem esse processo seletivo prévio e aceitam qualquer aluno?

É perceptível que, com o passar do tempo, tanto o MEC como o Inep têm envidado esforços para que a divulgação dos dados seja o retrato mais fiel possível das condições enfrentadas pelas escolas em cada uma das regiões brasileiras. Assim, se, em 2009, a divulgação dos resultados se dava numa lista simples, em 2010, a divulgação foi feita tendo por base a taxa de participação dos estudantes no exame, criando, assim, quatro categorias distintas. Em 2011, os resultados passaram a 
ser divulgados por área do conhecimento. Em 2012, a divulgação do desempenho individual dos alunos foi disponibilizada, também, para as próprias escolas, para que tenham um melhor acompanhamento pedagógico de seus alunos. Já em 2013, o Inep acrescentou à divulgação dos resultados outros dois critérios: o Inse (indicador socioeconômico das escolas) e a formação docente. Todas essas alterações na divulgação dos resultados são fruto da constatação, por parte do MEC e do Inep, de que o Enem, hoje, fornece dados para que, principalmente, a imprensa nacional estabeleça e divulgue um ranking de resultados por escolas, permitindo que haja uma maior justiça na comparação entre as escolas do país, considerando os contextos social, econômico e cultural.

Finalmente, dialogando com Bourdieu e Passeron, especialmente em suas obras Les Hèritiers (Os herdeiros) (1985) e A reprodução: elementos para uma teoria do sistema de ensino (1992), pode-se apontar para uma explicação teórica das indagações originadas no decorrer do estudo e explicitadas neste artigo. Nessas obras, Bourdieu e Passeron acentuam o papel da escola como o de legitimar as desigualdades de chances diante da cultura, a partir de critérios de julgamentos que ela emprega, os privilégios socialmente condicionados aos méritos e aos dons pessoais. Isso pode ser inferido para o caso analisado neste artigo, em relação às diferenças regionais associadas às condições econômicas e sociais e o parâmetro uniforme de avaliação utilizado pelo Enem.

Especialmente em Os herdeiros, a tese fundamental é a de que a desigualdade escolar e a desigualdade do acesso ao processo escolar permitem às classes dominantes constituir o monopólio da utilização do sistema escolar e de ver, através do sucesso profissional e social, a confirmação dos seus dons naturais e sociais. Em outras palavras, o sistema escolar é construído para os herdeiros do capital cultural e social, para quem já os têm. Isso pode ser inferido para o caso das diferenças do desempenho escolar apontadas nas edições do Enem analisadas neste artigo, dependendo da região e/ou da natureza pública ou privada das escolas.

\section{Notas}

1 Disponível em: <http://www.inep.gov.br>. Acesso em: 15 jun. 2015.

2 Disponível em: <http://download.inep.gov.br/download/enem/2009/notatecnicaenem_2009_embargo.pdf>. Acesso em fev. 2016 .

3 Disponível em: <http://portal.mec.gov.br/>. Acesso: 20 mar. 2015.

4 Disponível em: <http://agenciabrasil.ebc.com.br/>.

5 Disponível em: <http://memoria.ebc.com.br/agenciabrasil/noticia/2013-11-25/escolas-federais-obtem-maior-media-no-enem-2012 >. Acesso em: 20 jul. 2015.

6 O Inse de cada escola é a média do nível socioeconômico dos seus alunos distribuído em 7 níveis (sendo 7 o mais alto). O cálculo dessa medida foi feito a partir das informações fornecidas pelos alunos no preenchimento do questionário contextual. (Portal Brasil. Disponível em: <http://www.brasil.gov.br/educacao/2014/12/inep-divulga-resultado-do-enem-por-escola-2013>. Acesso em: 20 jul. 2015). 
7 É a proporção de professores de cada escola que leciona no ensino médio e tem a formação adequada, nos termos da lei. Os dados utilizados são fornecidos pela própria unidade de ensino, por meio do Censo Escolar da Educação Básica. (Portal Brasil. Disponível em: <http://www.brasil.gov.br/educacao/2014/12/ inep-divulga-resultado-do-enem-por-escola-2013>. Acesso em: 20 jul. 2015).

\section{Referências}

BONETI, Lindomar Wessler. Políticas públicas por dentro. 3. ed. Ijuí: Editora Unijuí, 2011.

BOURDIEU, Pièrre; PASSERON, Jean-Claude. A reprodução: elementos para uma teoria do sistema de ensino. 3. ed. Rio de Janeiro: F. Alves, 1992.

. Les Hèritiers - les étudiants e la culture. Paris: Les Éditions de Minuit, 1985.

DALBEN, Ângela I. L. de Freitas. Das avaliações exigidas às avaliações necessárias. In: VILLAS BOAS, Benigna Maria de Freitas (Org.). Avaliação: políticas e práticas. Campinas, SP: Papirus, 2002. p. 13-42.

KAUCHAKJE, Samira. Elaboração e planejamento de projetos sociais. Curitiba: Iesde Brasil S.A., 2008.

VIEIRA, Alboni M. D. P. Instituições escolares: memória, fontes, arquivos e novas tecnologias. In: SILVA, João Carlos da; ORSO, Paulino José; CASTANHA, André Paulo \& MAGALHÃES, Lívia Diana Rocha (Org.). História da educação: arquivos, instituições escolares e memória histórica. Campinas, SP: Alínea, 2013. p. 64-78. 